\title{
Primary bone lymphoma
}

INSERM

\section{Source}

INSERM. (1999). Orphanet: an online rare disease and orphan drug data base. Primary bone lymphoma. ORPHA:314684

Primary bone lymphoma is a rare lymphoid hemopathy defined as single or multiple tumors in the bone, not associated with infring ement or violation of other extranodal malignant lymph nodes outside the area. It usually presents with bone pain, nerve compression, a palpable mass or fracture, while systemic features (fever, night sweats, fatigue, loss of appetite, weight loss) are not common. 